\title{
Analysis of tomato matrix effect in pesticide residue quantification through QuEChERS and single quadrupole GC/MS
}

\author{
Ana M. Domínguez ${ }^{1 *}$, Fabian Placencia ${ }^{2}$, Francisco Cereceda $^{1}$, Ximena Fadic $^{1}$, and Waldo Quiroz ${ }^{2}$
}

The detection of pesticide in tomato (Solanum lycopersicum L.) matrix using Gas Chromatography hyphenated to Mass Spectrometry detector (GC/MS) can affect the sensitivity of the analysis by enhancement or suppression of their chromatography response, the percentages of recoveries and leading to errors in the quantification of the pesticides. In this study, the matrix effect was investigated using nine pesticides, and "Quick, Easy, Cheap, Effective, Rugged and Safe" (QuEChERS)-GC/MS analytical technique was validated for pesticides multiresidue analysis. The matrix effect was determined using not statistical and statistical procedures including ANOVA, with similar results. Strong negative matrix effect was found for the pesticides trifluralin, 4,4'-DDT, and permethrin, resulting in the increment of the chromatogram background and a decrease in their detection responses. Contrary, an enhancement induced by the matrix presence was obtained for carbaryl and azinphos methyl, showing a positive medium matrix effect. While, dimethoate, simazine, 4,4 'DDE, and iprodione did not exhibit matrix effect. The detection limits (LOD) obtained, varied from 0.003 to $0.1 \mathrm{mg} \mathrm{kg}^{-1}$. Reproducibility was less than $20 \%$ for each pesticide. Recoveries were found to be between $71 \%$ and $121 \%$, except for dimethoate, carbaryl, and azinphos methyl which reached values lower than $70 \%$. Recoveries relative standard deviations were less than 22\%. Quechers-GC/MS technique was used for evaluation of fresh commercial tomatoes samples, detecting carbaryl in all of them, but in concentration levels lower than the maximum residue limits according to regulations of Codex.

Key words: Matrix effect, QuEChERS, Solanum lycopersicum, statistical procedures.

\section{INTRODUCTION}

One of the main problems in the detection of pesticides residues in agricultural products are the matrix effect; the co-extractives compounds such as: pigments, fatty acids, sugars, among other, interfere with the detection of the pesticide making the cleanup of the final extract to play an important role in sample analysis (Fialkov et al., 2007). At present, there is not a unique extraction technique and cleanup methods which eliminate completely the matrix effect. Nevertheless, the "Quick, Easy, Cheap, Effective, Rugged and Safe" (QuEChERS) methodologies have been applied in many laboratories, with good results and high recoveries, for several complex matrices extractions, such as: soil (Nanita et al., 2009; Rashid et al., 2010), biological samples (Kalachova et al., 2011), and food (Wilkowska and Marek, 2011; Hou et al., 2013). This method was created by Anastassiades and coworkers for

${ }^{1}$ Universidad Técnica Federico Santa María, Departamento de Química, Av. España 1680, Valparaíso, Chile.

*Corresponding author (anamaria.dominguez@usm.cl).

${ }^{2}$ Pontificia Universidad Católica de Valparaíso, Instituto de Química, Av. Universidad 330, Curauma, Valparaíso, Chile.

Received: 30 July 2013.

Aceepted: 17 January 2014.

doi:10.4067/S0718-58392014000200004 the extraction of pesticides, which combines the isolation of pesticides from the complex matrix like food and the extract clean up (Anastassiades et al., 2003; Lehotay, 2007). Recently, the QuEChERS applications have been widely spread to determine other contaminants including cresols (García Pinto et al., 2011), benzene, toluene, ethylbenzene, and xylenes (BTEX) (Padilla-Sánchez et al., 2010), polycyclic aromatic hydrocarbons (PAHs) and polychlorinated biphenyls (PCBs) (Norli et al., 2011).

The matrix effect phenomenon in pesticide analysis had been studied (Lehotay et al., 2010; Kwon et al., 2012) using GC/MS and High Pressure Liquid Chromatography hyphenated to mass spectrometry detector (HPLC/MS). It was reported that, in the analysis of the pesticides by $\mathrm{GC} /$ MS, the analytes reacted with the remaining active sites of the deactivated liners, column and detector when the sample is injected as a solvent solution. This interaction is due to the polar groups like: hydroxyl, amine and phosphate (Kwon et al., 2012) present in the pesticide; as a consequence less amount of analyte than the injected one is detected. While if pesticides are injected in the presence of matrix, it may take place two different effects: (1) a matrix induce chromatographic response enhancement or (2) a matrix induce chromatographic response suppression. The first matrix effect occurs due to interactions of the matrix compounds with the remaining 
active sites of the liner, column and detector, which avoid pesticides losses by concepts of thermal degradation or by adsorption, leading to increment the detected pesticides signals (Hajšlová et al., 1998). The second effect it could happened when the pesticides interact and co-elute with the matrix compounds; and, as matrix compounds are not at trace level, the chromatogram background increase, producing a suppression of the chromatographic pesticide signal (Hajšlová et al., 1998).

How can be determined the effect of the matrix? Some authors use statistical comparison, the matrix effect is determine, through Fisher's (variance) and Student's test (means), between the slope of the pesticide calibration curve in the solvent solutions and the slope of the pesticide calibration curve in matrix extract solutions. Both curves could be prepared with or without internal standard (Guerrero, 2003; Ferrer et al., 2011; Moura et al., 2011). Also, it is had been reported for this purpose other statistical procedures like ANCOVA (Ahumada and Zamudio, 2011); or Principal Components Analysis (PCA) (de Sousa et al., 2012). Besides that, various studies report the extent of matrix effect (enhancement or suppression) (Kruve et al., 2009), and the matrix effect percentage (\% ME) (Economou et al., 2009; Ahumada et al., 2010).

Tomato (Solanum lycopersicum L.) was selected for our study because is a high consumption vegetable of diverse cultures, but also because it has a lot of health benefits including its content of lycopene which helps to decrease oxidative stress (Itziar et al., 2013). In addition, Chile has a high annual per capita tomato consumption, around 25 to $35 \mathrm{~kg}$; comparable with the USA and European countries (Flaño, 2012). Most of them are produced outdoor or in greenhouses with the well known indiscriminate use of pesticides. In this scope the development of a fast, cheap, and reliable pesticide QuEChERS extraction procedure using Gas Chromatography/Mass Spectrometry (GC/MS) detection bring a high interest regarding public health and Chilean regulation, especially for the internal market. The goals of this work were to determine the influence of tomato matrix in the detection of pesticides (trifluralin, dimethoate, simazine, carbaryl, 4,4'-DDE, 4,4'-DDT, iprodione, azinphos methyl and permethrin) by GC/MS, using the QuEChERS extraction procedure, in order to establish the correct quantitation methodology for a multiresidue determination method and at the same time, to validate the QuEChERS-GC/MS analytical technique.

\section{MATERIALS AND METHODS}

Reagents. Acetone and acetonitrile (pesticide grade) were purchased from Fisher Scientific (New York, USA). Pesticide neat standards: dimethoate (2-dimethoxyphosphinothioylthio- $N$-methylacetamide), trifluralin ( $\quad \alpha, \alpha, \alpha$-trifluoro-2,6-dinitro- $N, N$-dipropyl$p$-toluidine), simazine (6-chloro- $N, N$ '-diethyl- 1,3,5-triazine-2,4-diamine), carbaryl (1-naphthyl methylcarbamate), 4,4'-DDT (1-chloro-4-[2,2,2trichloro-1-(4-chlorophenyl)ethyl]benzene), 4,4'-DDE (1-chloro-4-[2,2-dichloro-1-(4-chlorophenyl)ethenyl] benzene), iprodione (3-(3,5-dichlorophenyl)- $N$-isopropyl2,4-dioxoimidazolidine-1-carboxamide), azinphos methyl (S-3,4-dihydro-4-oxo-1,2,3-benzotriazin-3ylmethyl $O, O$-dimethyl phosphorodithioate), and permethrin (3-phenoxybenzyl (1RS)-cis-trans-3-(2,2dichlorovinyl)-2,2- dimethylcyclopropanecarboxylate) (Pestanal, with more than $97 \%$ of purity, Sigma-AldrichFluka, Madrid, Spain). Certified pesticide liquid 10 $\mu \mathrm{L} \mathrm{mL} \mathrm{mL}^{-1}$ solutions were purchase by Dr. Ehrenstorfer, Germany. Sodium chloride and anhydrous magnesium sulphate (Emsure, Merck, Darmstadt, Germany); Selectra PSA (primary and secondary amine, United Chemical Technologies UCT, Horsham, Pennsylvania, USA); and the internal standard triphenylphosphate (TPP, Sigma Aldrich, Supelco, Bellefonte, Pennsylvania, USA). Certified pesticide liquid solutions and the stock solutions were stored in an amber capillary bottle at $4{ }^{\circ} \mathrm{C}$.

Table 1 shows the structure and the agricultural use of pesticides under study. It is worth noting that 4,4'-DDT was outlawed in Chile since 1984, but was included in this study due to its persistence and the persistence of its degradation compounds, being 4,4'-DDE its main breakdown product.

Stock solutions of individual pesticides were prepared in acetone, using the proper amount of each neat pesticide solid standard, to reach concentrations between 1000 to $3000 \mathrm{mg} \mathrm{L}^{-1}$.

Pesticides working solutions. The multi-residues working solutions were prepared in acetone, employing the adequate quantity of each individually stock solution, to reach $20 \mathrm{mg} \mathrm{L}^{-1}$ of concentration.

Solvent calibration solutions. The solvent calibration solutions were prepared in acetonitrile, using the multiresidue working solution to reach pesticide concentrations ranging from 0.01 to $1 \mathrm{mg} \mathrm{L}^{-1}$ and, adding $100 \mu \mathrm{L}$ of the internal standard (TPP), from its $15 \mathrm{mg} \mathrm{L}^{-1}$ working solution.

Matrix matched calibration solutions. Matrix matched calibration solutions were prepared in tomato blank acetonitrile extracts (obtained by QuEChERS), employing the multiresidue working solution to reach concentrations ranging from 0.01 to $1 \mathrm{mg} \mathrm{L}^{-1}$ and, adding $100 \mu \mathrm{L}$ of the internal standard (TPP), from its $15 \mathrm{mg} \mathrm{L}^{-1}$ working solution.

QuEChERS procedure. Two kilograms of organic tomatoes were sliced and homogenized using a commercial blender with stainless steel blades and glass vessel. After that, $10 \mathrm{~g}$ of this tomato pulp was weighed in 
Table 1. Structure and action of the pesticides under study,

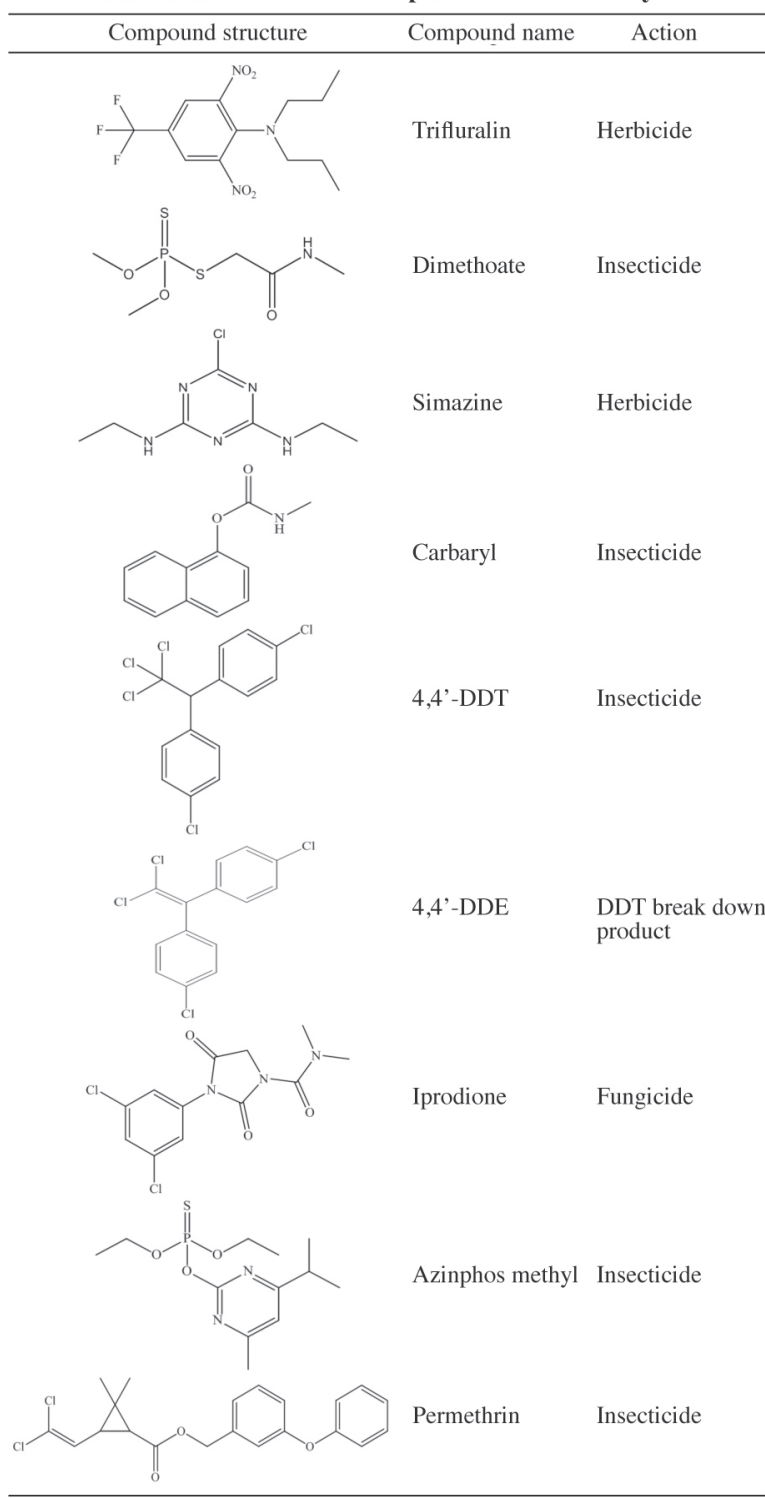

a $50 \mathrm{~mL}$ falcon centrifuge tube, and $10 \mathrm{~mL}$ of acetonitrile was added using a solvent dispenser. The mixture was vortex for $30 \mathrm{~s}$. Then, $4 \mathrm{~g}$ anhydrous $\mathrm{MgSO}_{4}$ and $1 \mathrm{~g}$ $\mathrm{NaCl}$ were added and the mixture was vortex again for $30 \mathrm{~s}$; after that, the tomato pulp and the upper organic acetonitrile extract containing the pesticides were isolated by centrifuging for $5 \mathrm{~min}$ at $5000 \mathrm{rpm}$ (Anastassiades et al., 2003).

The cleanup step was carried out pouring $8 \mathrm{~mL}$ of the upper acetonitrile layer into a $15 \mathrm{~mL}$ falcon centrifugation tube and adding $200 \mathrm{mg}$ of PSA sorbent and $1.2 \mathrm{~g}$ anhydrous $\mathrm{MgSO}_{4}$; after vortex for $30 \mathrm{~s}$, the mixture was centrifuged for $5 \mathrm{~min}$ at $5000 \mathrm{rpm}$ (Anastassiades et al., 2003). The organic extract was transferred directly into the autosampler vial for its chromatographic analysis, using a GC/MS-Selected Ion Recording (SIR) method.
Chromatographic analysis. For chromatographic analysis, Perkin Elmer equipment Clarus 680 GC hyphenated to SQ8C simple quadrupole mass spectrometry detector (Perkin Elmer, Waltham, Massachusetts, USA) was used. One microliter of the extract was injected in splitless mode, setting the injector port temperature at 200 ${ }^{\circ} \mathrm{C}$ and using a pulse of $2 \mathrm{~mL} \mathrm{~min}^{-1}$ for $1 \mathrm{~min}$. Samples were isolate employing the Elite-5ms (Perkin Elmer) capillary column of $30 \mathrm{~m} \times 0.25 \mathrm{~mm} \times 0.25 \mu \mathrm{m}$. The column oven was set at $80{ }^{\circ} \mathrm{C}$ for $2 \mathrm{~min}$, after that, temperature was increased to $180{ }^{\circ} \mathrm{C}$ at $20{ }^{\circ} \mathrm{C} \mathrm{min}-1$ of heating rate, then it was raised until $250{ }^{\circ} \mathrm{C}$ using a heating ramp of $4.5^{\circ} \mathrm{C}$ $\mathrm{min}^{-1}$ and maintained for $12 \mathrm{~min}$. Helium working flow was set at $1 \mathrm{~mL} \mathrm{~min}{ }^{-1}$. Mass spectrometer transfer line and the ionization source temperature were set at $200{ }^{\circ} \mathrm{C}$ and $170{ }^{\circ} \mathrm{C}$, respectively; and the Register Ion Monitoring $(\mathrm{SIR}=\mathrm{SIM})$ mode method was used for the analysis

The quantification $\mathrm{m} / \mathrm{z}$ fragment, chosen for each pesticide, was show underlined in Table 2. Quantification ion (or fragment) was selected considering that it is a fragment of high molecular weight and also has good intensity. For iprodione was chosen the $\mathrm{m} / \mathrm{z}=70$, because its high molecular weight fragments had quite low intensities. On the other hand, integration areas obtained for this compound and for azinphos methyl were low.

Table 2. Pesticides chemical family, molar mass, their relate retention time, and principal $\mathbf{m} / \mathbf{z}$ fragments.

\begin{tabular}{|c|c|c|c|c|}
\hline Pesticide & Chemical family & $\begin{array}{c}\text { Molar } \\
\text { mass }\end{array}$ & $\begin{array}{c}\text { Retention } \\
\text { time }\end{array}$ & $\begin{array}{c}\text { Main } \\
\text { fragments }\end{array}$ \\
\hline & & $\mathrm{g} \mathrm{mol}^{-1}$ & $\min$ & \\
\hline Trifluralin & Dinitroaniline & 335.28 & 9.37 & $145 / 264 / \underline{306}$ \\
\hline Dimethoate & Organothiophosphate & 229.26 & 10.30 & $87 / 93 / \underline{125}$ \\
\hline Simazine & Triazine & 201.66 & 10.46 & $173 / 186 / \underline{\underline{201}}$ \\
\hline Carbaryl & Carbamate & 201.22 & 13.54 & $115 / 116 / 144$ \\
\hline 4,4'-DDE & Organochlorine & 318.03 & 21.47 & $\underline{246} / 248 / 318$ \\
\hline 4,4'-DDT & Organochlorine & 354.50 & 25.22 & $\overline{165} / \underline{235} / 237$ \\
\hline TPP & Organophosphate & 326.28 & 26.24 & $\underline{326} / \overline{325} / 77$ \\
\hline Iprodione & Dicarboximide & 330.17 & 27.28 & $\underline{70} / 187 / 314$ \\
\hline Azinphos methyl & Organophosphate & 317.32 & 29.10 & $\overline{77} / 132 / \underline{160}$ \\
\hline Permethrin & Pyrethroid & 391.30 & $32.23^{*}$ & $163 / 165 / 183$ \\
\hline
\end{tabular}

"Retention time of cis-permethrin.

\section{RESULTS AND DISCUSSION}

Chromatographic analysis. The standards were analyzed using a full scan $(50-400 \mathrm{~m} / \mathrm{z})$ method in order to determine the retention time and main fragments for each pesticide; then the Register Ion Monitoring (SIR = SIM) mode method was used for all the analysis. The injector port, ionization source and transfer line temperature were optimized to improve the instrumental pesticide response.

Temperature optimization. During instrumental optimization tests, only one parameter was changed each time: injector temperature, source temperature and transfer line temperature, keeping the helium flow at $1 \mathrm{~mL} \mathrm{~min}^{-1}$ and the oven temperature program as described above. The injector temperatures studied were 150, 180, 200, and $220{ }^{\circ} \mathrm{C}$; ionization source $\left(150\right.$ and $\left.170{ }^{\circ} \mathrm{C}\right)$ and; transfer 
line $\left(180,200,210^{\circ} \mathrm{C}\right)$. The plotting area obtained under each condition for all the pesticides is show in Figure 1a, $1 \mathrm{~b}$, and $1 \mathrm{c}$; data were acquired in triplicate.

Dimethoate and simazine integration areas were higher when the electron energy was reduced, from 70 to $65 \mathrm{eV}$; this instrumental change did not influence significantly the other pesticides studied.

It was observed that the integration area of each pesticide increased as the temperature of the injector port was increased until $200{ }^{\circ} \mathrm{C}$ (Figure 1a). A further increment on the temperature of the injector port produced a significant decrease in some pesticide integration area like: carbaryl, trifluralin, 4,4'-DDT, and 4,4'-DDE; while permethrin, azinphos methyl an iprodione experience an increase in their integration areas. This effect is probably related with this pesticides thermal stability and possible losses by vaporization, adsorption or degradation at the injector port under the working conditions.

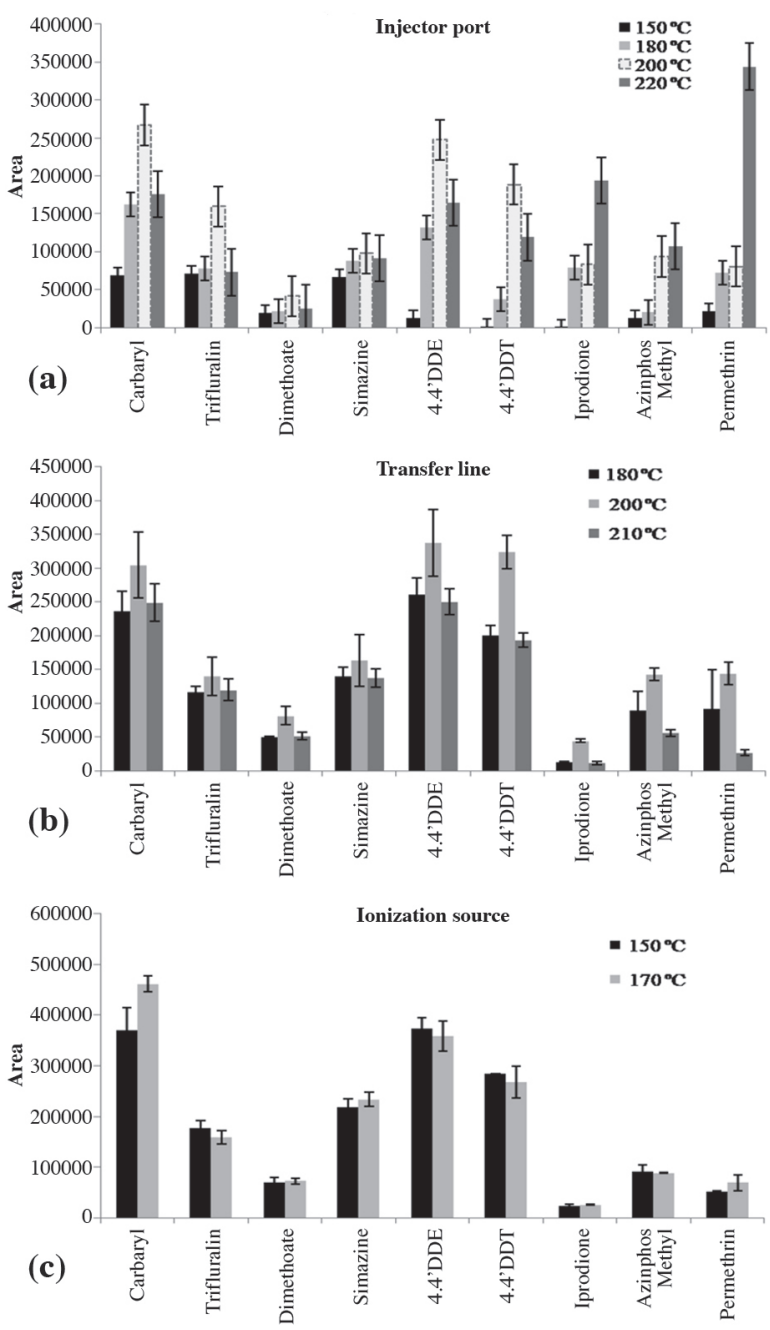

Figure 1. Graphical representation of the obtained areas for each pesticide, with the respective standard deviation bar, for the temperature optimization test results of: (a) injector port, (b) transfer line, and (c) ionization source.
Figure $1 \mathrm{~b}$ shows the pesticides integration area behavior with respect to the transfer line temperature variation; all the compounds studied increase their areas with temperature, until $200{ }^{\circ} \mathrm{C}$. When transfer line was set at $200{ }^{\circ} \mathrm{C}$, all the pesticides reach maximum integration areas. When the temperature of the transfer line was above $200{ }^{\circ} \mathrm{C}$ the integration area was decreased.

On the other hand, the increment in the source temperature from 150 to $170{ }^{\circ} \mathrm{C}$ only has a significant influence on carbaryl and permethrin integration areas (Figure 1c). This could be associated with a better fragmentation through amide and ester group of carbaryl and permethrin structures during the ionization step, which help the formation of 144 and $183 \mathrm{~m} / \mathrm{z}$ fragments. These fragments were used respectively for quantitation. While, reducing the source temperature to $120^{\circ} \mathrm{C}$ cause a severe loss of the detector sensitivity for all the pesticides under study.

The response of each pesticide was different in relation to their thermal stability, fragmentation and volatilization, so was necessary to get to a compromise based on the obtained results. In the case of carbaryl, it was affected with all the temperature studied, but it had a positive response on its integration areas until $200{ }^{\circ} \mathrm{C}$; probably, above this temperature carbaryl becomes thermally unstable. It is known, that carbamates are thermally sensible and there are prone to degradation (Przybylski and Bonnet, 2009). Possibly, that is the reason associated with the appearance of 1-naphthol in our chromatogram; this compound could be produced due to the existence of fragile bonds on the carbaryl structure and/or by hydrolysis (Przybylski and Bonnet, 2009). It was observed two signals with very similar mass spectrum, except for the fragment $\mathrm{m} / \mathrm{z} 201$, at retention times 8.01 and $13.54 \mathrm{~min}$. An exploratory assay, with solutions of carbaryl in acetonitrile at different $\mathrm{pH}$ confirmed the influence of the solution $\mathrm{pH}$ in the obtained value of the ratio of carbaryl/1-naphthol; in which was higher at $\mathrm{pH} 4$ than $\mathrm{pH} 6$.

Finally, the optimal working temperatures for the injector port, transfer line and source were set at: 200 , 200 , and $170{ }^{\circ} \mathrm{C}$, respectively.

Selectivity. The GC/MS-SIR method performed the scanning of the three main characteristic fragments for each pesticide, in their retention time segments. Figure $2 \mathrm{a}$ and $2 \mathrm{~b}$ shows the total Selected Ion Recording (SIR) chromatograms obtained for the tomato blank extract (lower chromatogram signals) and for the $0.5 \mathrm{mg} \mathrm{kg}^{-1}$ spiked tomato blank extract (upper chromatogram). From left to right the chromatogram (a) shows the signals of trifluralin, dimethoate, simazine, carbaryl, and 4,4'-DDE; and chromatogram (b): 4,4'-DDT, TPP (internal standard), iprodione, azinphos methyl, and permethrin. There is not interference compounds in the analyzed segments; the organic tomato extract obtained by QuEChERS could be used as matrix blank for our studies. 
(a)

(b)
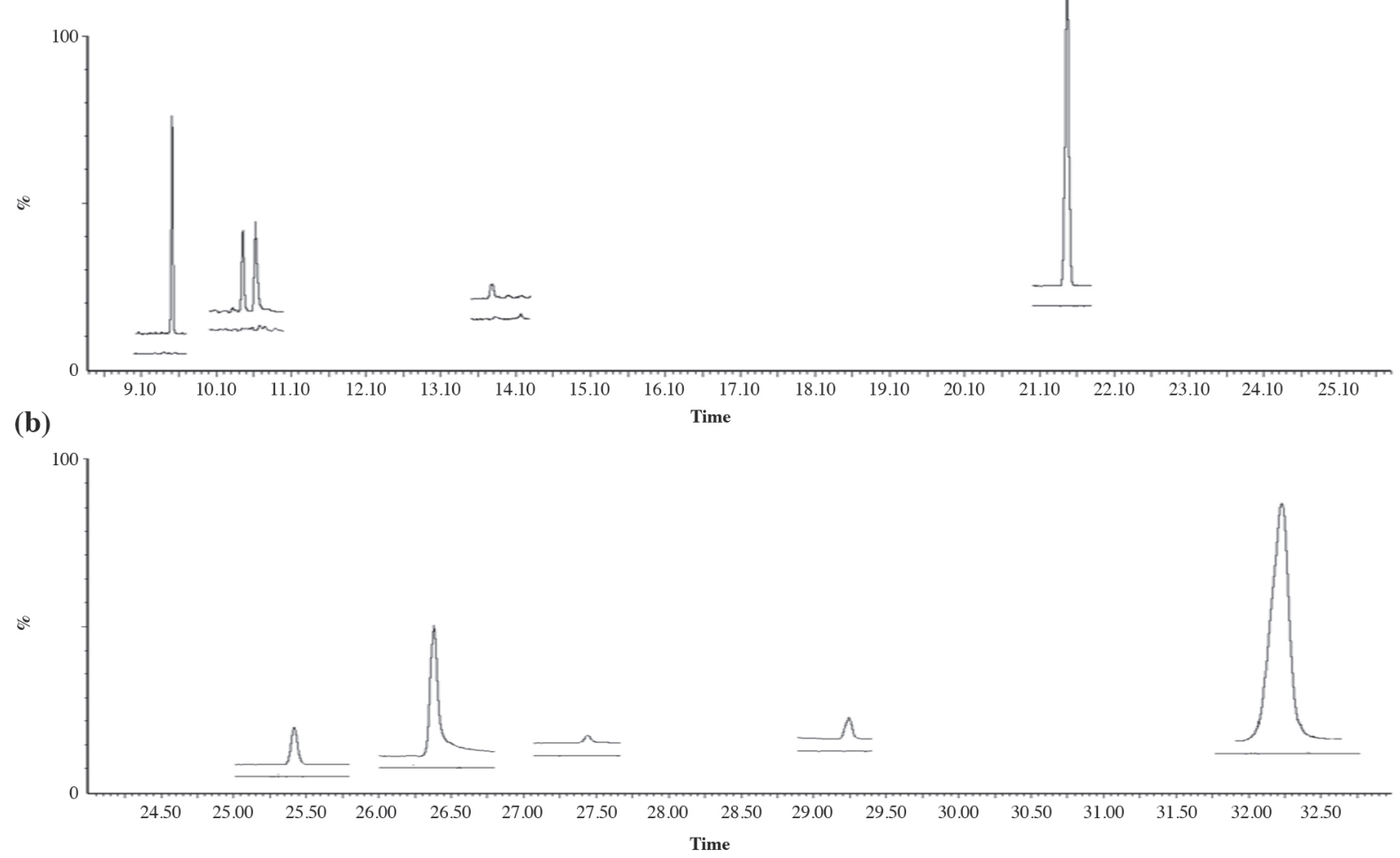

Figure 2. Selective Ion Recording (SIR) chromatograms (a) from $9.00 \mathrm{~min}$ to $25.10 \mathrm{~min}$; and (b) from $25.10 \mathrm{~min}$ to $33.00 \mathrm{~min}$; obtained for the tomato blank extract, after the tomato pulp extraction using "Quick, Easy, Cheap, Effective, Rugged and Safe" (lower chromatogram) and for the $0.5 \mathrm{mg} \mathrm{L}^{-1}$ pesticide spiked tomato blank extract [upper chromatogram]. Analytes from left to right: (a) trifluralin, dimethoate, simazine, carbaryl, and 4,4'-DDE; (b) 4,4'-DDT, triphenylphosphate (TPP), iprodione, azinphos methyl, and permethrin.

Determination of matrix effect. Different test for the determination of matrix effect and matrix effect extent had been reported in the literature (Hajšlová et al., 1998; Guerrero, 2003; Kruve et al., 2009; Ferrer et al., 2011; Moura et al., 2011; Ahumada and Zamudio, 2011; de Sousa et al., 2012; Kwon et al., 2012), some of them were tested in this scope, besides the ANOVA procedure.

In our study the matrix effect was determined for each pesticide by means of statistical comparison between three matrix match calibration curves responses, respect to three direct solvent calibration curves responses. This comparison was performed for each agrochemical compound at 0.05 significance level, employing Microsoft Excel for the statistical Student test (means comparison) and Fisher's test (variances comparison), of the respective slope values. Each curve had five concentration levels of pesticide and a blank; they were prepared in different days and injected in triplicate. The internal standard was added to all the concentration levels including the blank, in order to control fluctuations between injections. Table 3 shows the average slopes values from solvent and matrix calibration curves and their statistical comparisons; considering as null hypothesis the similarity between the respective average solvent and matrix slopes.
These results show that $56 \%$ of the studied pesticides had matrix effect. Those compounds had significant differences between their solvent and matrix slopes values, or what it is the same, the similarity hypothesis between their solvent and matrix slopes values was rejected (Table 3 , column 4). The null hypothesis was accepted only for dimethoate, 4,4'-DDE, iprodione, and simazine; whose slopes average values in matrix and solvent were similar.

Matrix effect estimation using ANOVA for two sample comparison. Alternative, the ANOVA was used to confirm these results, considering the data normal distribution and employing 0.05 of significance level. In this case all the solvent and the matrix calibration curves data were considered as they were two independent samples (for comparison purpose). The ANOVA test returns a P-value, which takes into account the mean difference, the variance and the data size. A Pcalc value $<0.05$ indicates the existence of significant differences in group expression data; $P$ values are show in Table 3. The results obtained using both procedures (1) the statistical comparison of the slopes of calibration curves and (2) through the statistical comparison of all the data set, between the external calibration curve (solvent curve) and the matrix match calibration curve (matrix curve), are in agreement. 
Table 3. Tomato matrix effect: solvent and matrix calibration curves slope values; results from Student (similarity hypothesis) and ANOVA ( $P_{\text {calc }}$ and significance) statistical tests; and the calculated percentage of matrix effect ( $\% \mathrm{ME})$.

\begin{tabular}{lllllll}
\hline & $\begin{array}{c}\text { Solvent } \\
\text { slope }\end{array}$ & $\begin{array}{c}\text { Matrix } \\
\text { slope }\end{array}$ & $\begin{array}{c}\text { Similarity } \\
\text { slopes } \\
\text { hypothesis }\end{array}$ & $\begin{array}{c}\mathrm{P}_{\text {calc. }} \\
\text { bilateral }\end{array}$ & $\begin{array}{l}\text { Significance } \\
\text { Pesticide }\end{array}$ & $\begin{array}{c}\% \\
\text { ME }\end{array}$ \\
\hline Trifluralin & 2.46 & 1.08 & rejected & 0.0058 & Significant & $\underline{-138}$ \\
Dimethoate & 0.170 & 0.178 & accepted & 0.53 & Non & 1.0 \\
Simazine & 0.582 & 0.751 & accepted & 0.87 & Non & 17 \\
Carbaryl & 0.0210 & 1.25 & rejected & 0.00040 & Significant & $\underline{122}$ \\
4,4'-DDE & 2.97 & 3.19 & accepted & 0.48 & Non & 22 \\
4,4'-DDT & 2.30 & 1.70 & rejected & 0.029 & Significant & $\underline{-60}$ \\
Iprodione & 0.261 & 0.374 & accepted & 0.26 & Non & 11 \\
Azinphos methyl & 0.0183 & 0.310 & rejected & 0.0032 & Significant & $\underline{29}$ \\
Permethrin & 7.78 & 5.39 & rejected & 0.0021 & Significant & $\underline{-239}$ \\
\hline
\end{tabular}

After determine the existence of tomato matrix effect in more than $50 \%$ of our studied pesticides, the matrix effect extension was calculated to elucidate the influence of the presence of matrix in the analyte response.

Estimation of the matrix effect extent. The type or extent of the matrix effect (suppression or enhancement) was evaluated through the matrix effect percentage $(\%$ ME) calculation. This percentage was calculated from literature report (Ferrer et al., 2011) as: the percentage of the difference between the slopes values of the matrix match calibration curve and the solvent one. So, the \% ME could be negative or positive and would be classified in three categories (Ferrer et al., 2011): no matrix effect; medium matrix effect and; strong matrix effect, depending of the signs and the \% ME values, as shows Table 4. No matrix effect is considered as the values of $\% \mathrm{ME}$ are into the pesticide accepted analysis repeatability range values $( \pm 20 \%)$. In this case our own repeatability values have been considered.

The obtained \% ME values for each pesticide are reported in Table 3 . From the results, $44 \%$ of the studied pesticides had strong matrix effect, $22 \%$ medium, and $33 \%$ have not matrix effect.

Trifluralin, 4,4'-DDT, and permethrin have strong negative matrix effect, showing a great suppression of their signals in the presence of tomato matrix. This fact could probably be associated with the presence of coextractives compounds, which reduced these pesticides ionization. Similar results had been reported for permethrin in tomato matrix but using Electron Capture Detector (ECD) and solid liquid partition (de Sousa et al., 2012); while contrary to our results, it have been reported the existence of tomato matrix effect for iprodione with Nitrogen and Phosphorous Detector (NPD) and ECD detection, although the matrix effect extent was not informed (Guerrero, 2003). Negative matrix effect had

Table 4. Literature matrix effect (ME) categories.

\begin{tabular}{lll}
\hline \multirow{2}{*}{$\begin{array}{l}\text { Matrix effect } \\
\text { classification }\end{array}$} & \multicolumn{2}{c}{ ME values } \\
\cline { 2 - 3 } & Positive values & Negative values \\
\hline No matrix effect & $20 \%$ & $-20 \%$ \\
Medium matrix effect & $20 \%$ to $50 \%$ & $-20 \%$ to $-50 \%$ \\
Strong matrix effect & More than 50\% & Less than $-50 \%$ \\
\hline
\end{tabular}

been found also, for other pesticides and matrices, like apple (Ahumada et al., 2010).

Azinphos methyl exhibit a \% ME categorized as medium matrix effect. Dimethoate, iprodione, and simazine results are in the range of the compounds with no matrix effect (Ferrer et al., 2011). These results were in agreement with the statistical tests, except for 4,4'-DDE which classifies within the medium matrix effect category, but with a $\% \mathrm{ME}$ value of 22 , quite close to the no matrix effect compounds.

A second method used for evaluation of the matrix effect extent is the calculation of $\% \mathrm{ME}$, through the ratio of the matrix extract pesticide spiked area and the solvent spiked area for one or more concentration level and, for each pesticide or analyte; employing the expression giving in the following equation (Kruve et al., 2008):

$\% \mathrm{ME}=\left(\right.$ analyte $_{\text {matrix spike area }} /$ analyte $\left._{\text {solvent area }}\right) \times 100 \quad$ [1]

Table 5 show the \% ME results, calculated for a concentration level of $0.10 \mathrm{mg} \mathrm{kg}^{-1}$, using the analytes areas relative to the internal standard. These results were also consistent with previously reported in Table 3 .

Although it had been reported that the matrix effect percentage in pesticide analysis (calculated by this procedure) is more significant at lower concentration levels than for higher concentration levels, at higher concentration levels the ME have a tendency to equality (de Sousa et al., 2012).

More than $50 \%$ of the studied pesticides had matrix effect, for quantitation purpose must be used the matrix match calibration procedure to avoid under or over estimation of the sample results.

Reproducibility and repeatability. The mean reproducibility expressed as \% relative standard deviation (RSD), obtained in three measurements performed per day, in three different days with newly organic tomato sample spiked with $0.25 \mathrm{mg} \mathrm{kg}^{-1}$ and extracted by QuEChERS, of each pesticide was less than $20 \%$. While the obtained repeatability for carbaryl, iprodione, and azinphos methyl was $27 \%, 22 \%$, and $21 \%$, respectively.

Detection and quantification limits. For each pesticide, the detection limit (LOD) was calculated as the concentration corresponding to three times of the standard

Table 5. Matrix effect (ME) extent results and its relative standard deviation (RSD) values evaluated for $0.1 \mathrm{mg} \mathrm{kg}^{-1}$ concentration level.

\begin{tabular}{lrccl}
\hline Pesticide & $\begin{array}{c}\% \mathrm{ME}_{0.10} \\
\left(\mathrm{mg} \mathrm{kg}^{-1}\right)\end{array}$ & $\begin{array}{r}\mathrm{RSD} / \% \\
\mathrm{ME}_{\text {category value }}\end{array}$ & $\begin{array}{c}\text { ME } \\
\text { extent }\end{array}$ \\
\hline Trifluralin & 24 & 4 & $<100 \%$ & suppression \\
Dimethoate & 117 & 23 & $\cong 100 \%$ & without $\mathrm{ME}^{*}$ \\
Simazine & 94 & 7 & $\cong 100 \%$ & without ME \\
Carbaryl & 470 & 136 & $>100 \%$ & enhancement \\
4,4'-DDE & 102 & 14 & $\cong 100 \%$ & without ME \\
4,4'-DDT & 85 & 3 & $<100 \%$ & suppression \\
Iprodione & 90 & 8 & $\cong 100 \%$ & without ME \\
Azinphos methyl & 788 & 30 & $>100 \%$ & enhancement \\
Permethrin & 62 & 6 & $<100 \%$ & suppression \\
"No matrix effect. & & &
\end{tabular}


deviation (3S) of 10 tomato extract blank solutions and the quantification limit (LOQ) was based on 10 times the standard deviation (10S). The detection and quantification limit were calculated considering the internal standard and the matrix match calibration slope.

The LOD for trifluralin, dimethoate, simazine, carbaryl, 4,4'-DDE, 4,4'-DDT, iprodione, azinphos methyl, and permethrin were: $0.02,0.1,0.05,0.01,0.005,0.004,0.01$, 0.04 , and $0.003 \mathrm{mg} \mathrm{kg}^{-1}$, respectively. The calculated LOQ values and other validation results are reported in Table 6 , including the correlation coefficient values (r) for each calibration curve, which indicates a linear relationship between the areas and concentrations values (ANOVA regressions $\mathrm{P}$-values $<0.05$ were found at $95 \%$ confidence level), from the LOQ values to $0.75 \mathrm{mg} \mathrm{kg}^{-1}$.

Recovery. The recovery percentage was determined for a spiked 0.25 and $0.75 \mathrm{mg} \mathrm{kg}^{-1}$ of organic tomato (Table 6). This percentage depends of the pesticide and the concentration level. Lower recoveries less than $70 \%$ were reaching for azinphos methyl and dimethoate in both levels and for carbaryl in the lower concentration level; while trifluralin had recoveries values $>120 \%$ in

Table 6. Validation parameters results for pesticide analysis by "Quick, Easy, Cheap, Effective, Rugged and Safe" (QuEChERS) and Gas Chromatography hyphenated with Mass Spectrometry detection (GC/MS).

\begin{tabular}{llccccc}
\hline & & & & \multicolumn{2}{c}{ Recovery } \\
\cline { 4 - 7 } Pesticide & \multicolumn{1}{c}{$\begin{array}{c}\text { Matrix match } \\
\text { equation }\end{array}$} & & & & $0.25 \mathrm{mg}$ & $0.75 \mathrm{mg}$ \\
$\mathrm{kg}^{-1}$
\end{tabular}

${ }^{\mathrm{a}}$ Mean of the results and relative standard deviation (RSD), obtained in triplicate samples.

"Quantification Limit (LOQ). both spiking levels; an extra study with this analyte reveal recoveries percentages in the expected range when, the calibration curve is prepared by spiking the tomato pulp in different concentration levels with the internal standard and; the analyte goes through all the extraction procedure. The other pesticides studies showed a recovery percentage between $70 \%$ and $120 \%$ (SANCO, 2011), which is the accepted range for this kind of analysis.

Real sample analysis. Four commercial samples were evaluated in triplicate. The chromatograms were acquired using the single quadrupole GC/MS-SIR method, after the extraction of the samples by QuEChERS. From our results the pesticide carbaryl was detected in all the samples and, azinphos methyl in one of them; both under their quantification limits. Those pesticides were also under their respective MRL values, reported for tomatoes by Codex Alimentarius ( 5 and $1 \mathrm{mg} \mathrm{kg}^{-1}$ ). Also, it was found a signal in the retention time segment of the $4,4^{\prime}$-DDE, for all the tomatoes samples with concentrations values close to the LOQ $\left(0.02 \mathrm{mg} \mathrm{kg} \mathrm{kg}^{-1}\right)$. These concentrations levels were under the maximum extraneous residue limit established for carrot $\left(0.2 \mathrm{mg} \mathrm{kg}^{-1}\right)$ by Codex. Probably, this residual compound was generated by the degradation of the remaining traces of 4,4'-DDT in soils, which was a persistent pesticide used until 1984's. In a previous Chilean government study was found at national level sampling, traces of DDT in potatoes, but not in tomatoes or any other vegetable product (SAG, 2006). Figure 3 shows a chromatogram of one of the commercial sample analyzed, where the highest signal belongs to TPP (internal standard).

\section{CONCLUSIONS}

From all the pesticides studied, carbaryl signals were influenced by changing temperature in the injector port, transfer line, and ionization source. This compound was thermally unstable, and fragments to give 1-naphthol.

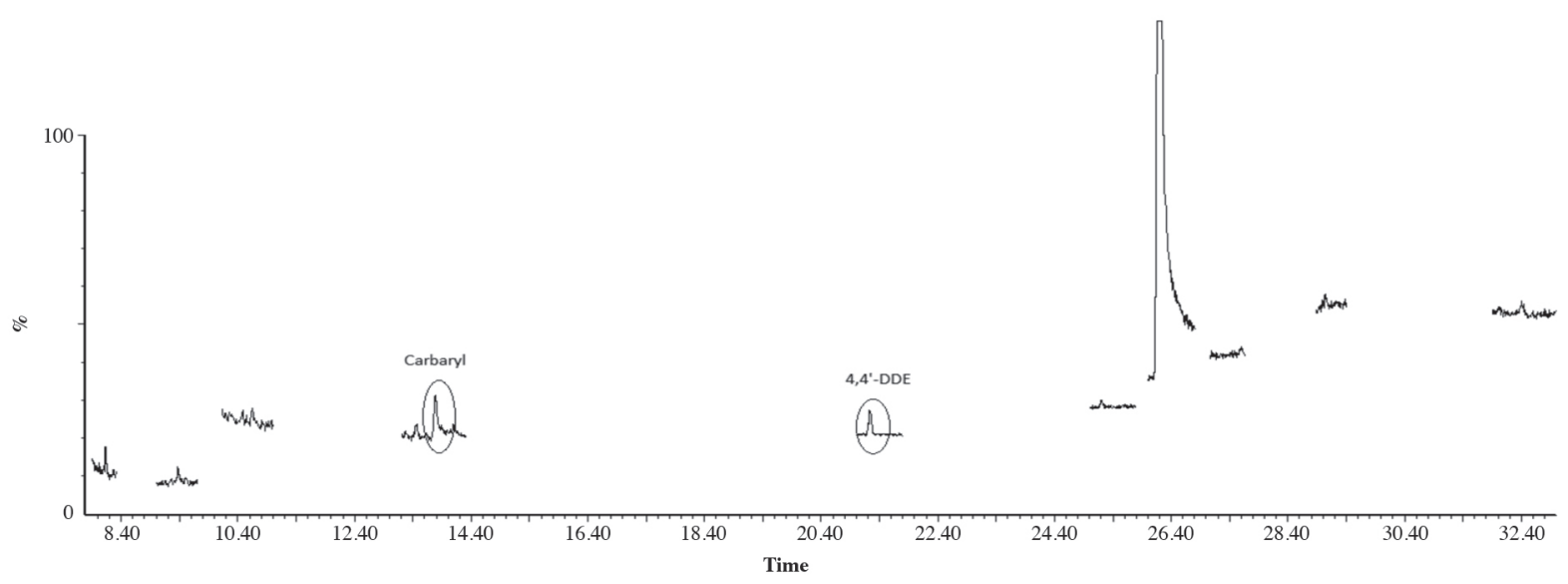

Figure 3. Commercial tomato chromatogram, obtained by Gas Chromatography hyphenated with Mass Spectrometry detection using Ion Selective Recording mode (GC/MS-SIR). 
Changes in the transfer line temperature affected the chromatography responses of the pesticides studied. The optimal temperatures conditions for the Selected Ion Recording (SIR) mode analysis were $200{ }^{\circ} \mathrm{C}$ at the injector port and mass inlet transfer line and $170{ }^{\circ} \mathrm{C}$ at ionization source. Nine pesticides were extracted from tomato using the QuEChERS procedure, and from them $56 \%$ showed matrix effect. The detection of dimethoate, simazine, 4,4'-DDE, and iprodione was not influenced by the matrix tomato. The matrix effect was estimated through non statistical and statistical procedures. The ANOVA for two sample comparison was in agreement with the non statistical \%ME calculated using the percentage of the ratio between the analyte spiked matrix area against the area of the analyte in the solvent solution, at one concentration level; and also was in agreement with the statistical student test for slopes comparison of the pesticide calibration curves in solvent and matrix, respectively. From all the studied pesticides, $44 \%$ had strong matrix effect (enhancement or suppression), where trifluralin, 4,4'-DDT, and permethrin experience a matrix-induced chromatographic response suppression, contrary to carbaryl, which experience a matrix-induced chromatographic response enhancement. As result, for quantification of pesticides residue in tomato was necessary to use a calibration curve in the presence of matrix or "matrix match calibration" procedure. The analytical method was validated giving reproducibility values $\leq 20 \%$ and recoveries between $70 \%$ and $120 \%$ except for trifluralin (higher recoveries), azinphos methyl, dimethoate, and carbaryl (lower recoveries). Detection limit values ranged from 0.003 to $0.1 \mathrm{mg}$ $\mathrm{kg}^{-1}$ and the quantification limit 0.01 to $0.4 \mathrm{mg} \mathrm{kg}-1$. Dimethoate, simazine, and azinphos methyl had the higher quantification limits $\left(>0.1 \mathrm{mg} \mathrm{kg}^{-1}\right)$.

\section{ACKNOWLEDGEMENTS}

The authors want to thank the financial support of CONICYT through the Integration Project nr 790950042010 and FONDEF Project nr D09I1070; also to the DGIP-UTFSM support in the course of the Internal Project $\mathrm{nr}$ 131152, and the gently collaboration of the organic farmer Mr. Daniel Rabb, and the Dr. Carmen Leiva English translation.

\section{LITERATURE CITED}

Ahumada, A.F., A. Diego, D. Guerrero, y A. Jairo. 2010. Estudio del efecto matriz en el análisis de plaguicidas por cromatografía de gases. VITAE, Revista de la Facultad de Química Farmacéutica de la Universidad de Antioquia 17:51-58.

Ahumada, D.A., and A.M. Zamudio. 2011. Analysis of pesticide residues in tomato using QuEChERS sample preparation and Ultra Fast Liquid Chromatography coupled to Mass Spectrometry. Revista Colombiana de Química 40:227-246.

Anastassiades, M., S.J. Lehotay, D. Stajnbaher, and F.J. Schenck. 2003. Fast and easy multiresidue method employing acetonitrile extraction/partitioning and "dispersive solid-phase extraction" for the determination of pesticide residues in produce. Journal AOAC International 86:412-431. Available at http://naldc.nal.usda.gov/ download/555/PDF (accessed February 2013).

de Sousa, F.A., A.I. Guido, M.E. Lopes, R.F. Teófilo, A.A. Neves, and G.P. de Pinho. 2012. Evaluation of matrix effect on the GC response of eleven pesticides by PCA. Food Chemistry 135:179185. doi:10.1016/j.foodchem.2012.04.063.

Economou, A., H. Botitsi, S. Antoniou, and D. Tsipi. 2009. Determination of multi-class pesticides in wines by solid-phase extraction and liquid chromatography-tandem mass spectrometry. Journal of Chromatography A 1216:5856-5867. doi:10.1016/j. chroma.2009.06.031.

Ferrer, C., A. Lozano, A. Agüera, A. Jiménez, and A.R. Fernández. 2011. Overcoming matrix effects using the dilution approach in multiresidue methods for fruits and vegetables. Journal of Chromatography A 1218:7634-7639. doi:10.1016/j. chroma.2011.07.033.

Fialkov, A.B., U. Steiner, S.J. Lehotay, and A. Amirav. 2007. Sensitivity and noise in GC-MS: Achieving low limits of detection for difficult analytes. International Journal of Mass Spectrometry 260:31-48. doi:10.1016/j.ijms.2006.07.002.

Flaño, A. 2012. Situación del tomate para consumo fresco. Oficina de Estudios y Políticas Agrarias (ODEPA), Ministerio de Agricultura, Gobierno de Chile, Santiago, Chile. Available at http://www.odepa.gob.cl/odepaweb/publicaciones/doc/6395.pdf (accessed May 2013).

García Pinto, C., S. Herrero, J.L. Pérez, and B. Moreno. 2011. A simplified Quick, Easy, Cheap, Effective, Rugged and Safe approach for the determination of trihalomethanes and benzene, toluene, ethylbenzene and xylenes in soil matrices by fast gas chromatography with mass spectrometry detection. Analytica Chimica Acta 689:129-136. doi:10.1016/j.aca.2011.01.023.

Guerrero, J.A. 2003. Estudio de residuos de plaguicidas en frutas y hortalizas en áreas específicas de Colombia. Revista Agronomía Colombiana 21:198-209. Available at http://www.redalyc.org/ articulo.oa?id=180317974009 (accessed January 2013).

Hajšlová, J., K. Holadová, V. Kocourek, J. Poustka, M. Godula, P. Cuhra, et al. 1998. Matrix-induced effects: a critical point in the gas chromatographic analysis of pesticide residues. Journal of Chromatography A 800:283-295. doi:10.1016/S00219673(97)01145-X.

Hou, X., M. Han, X. Dai, X. Yang, and S. Yi. 2013. A multi-residue method for the determination of 124 pesticides in rice by modified QuEChERS extraction and gas chromatography-tandem mass spectrometry. Food Chemistry 138:1198-1205. doi:10.1016/j. foodchem.2012.11.089.

Itziar, A., A. Perez, S. Navas, I. Bondia, M.A. Zulet, and J.A. Martinez. 2013. A regular lycopene enriched tomato sauce consumption influences antioxidant status of healthy youngsubjects: A crossover study. Journal of Functional Foods 5:28-35. doi:10.1016/j.jff.2012.07.007.

Kalachova, K., J. Pulkrabova, L. Drabova, T. Cajka, V. Kocourek, and J. Hajslova. 2011. Simplified and rapid determination of polychlorinated biphenyls, polybrominated diphenyl ethers, and polycyclic aromatic hydrocarbons in fish and shrimps integrated into a single method. Analytica Chimica Acta 707:84-91. doi:10.1016/j.aca.2011.09.016.

Kruve, A., I. Leito, and K. Herodes. 2008. Matrix effects in pesticide multi-residue analysis by liquid. Journal of Chromatography A 1187:58-66. doi:10.1016/j.chroma.2008.01.077.

Kruve, A., I. Leito, and K. Herodes. 2009. Combating matrix effects in LC/ESI/MS: The extrapolative dilution approach. Analytica Chimica Acta 651:75-80. doi:10.1016/j.aca.2009.07.060.

Kwon, H., S.J. Lehotay, and L. Geis-Asteggiante. 2012. Variability of matrix effects in liquid and gas chromatography-mass spectrometry analysis of pesticide residues after QuEChERS sample preparation of different food crops. Journal of Chromatography A 1270:235245. doi:10.1016/j.chroma.2012.10.059. 
Lehotay, S.J. 2007. Determination of pesticide residues in foods by acetonitrile extraction and partitioning with magnesium sulfate: Collaborative study. Journal of AOAC International 90:485-520.

Lehotay, S.J., K. Ae Son, H. Kwon, U. Koesukwiwat, W. Fu, K. Mastovska, et al. 2010. Comparison of QuEChERS sample preparation methods for the analysis of pesticide residues in fruits and vegetables. Journal of Chromatography A 1217:2548-2560. doi:10.1016/j.chroma.2010.01.044.

Moura, G.C.R., R.M.O. Freguglia, R.P.Z. Furlani, N.H. Torres, and V.L.Tornisielo. 2011. Determination of pesticide residues in tomato using dispersive solid-phase extraction and gas chromatography/ ion trap mass spectrometry. Journal of Brazilian Chemical Society 22:1701-1708. doi:10.1590/S0103-50532011000900012.

Nanita, S.C., A.M. Pentz, J. Grant, E. Vogl, T.J. Devine, and R.M. Henze. 2009. Mass spectrometric assessment and analytical methods for quantitation of the new herbicide aminocyclopyrachlor and its methyl analogue in soil and water. Analytical Chemistry 81:797-808. doi:10.1021/ac8020642.

Norli, H.R., A. Christiansen, and E. Deribe. 2011. Application of QuEChERS method for extraction of selected persistent organic pollutants in fish tissue and analysis by gas chromatography mass spectrometry. Journal of Chromatography A 1218:7234-7241. doi:10.1016/j.chroma.2011.08.050

Padilla-Sánchez, J.A., P. Plaza, R. Romero, A. Garrido, and J.L. Martínez. 2010. Application of a quick, easy, cheap, effective, rugged and safe-based method for the simultaneous extraction of chlorophenols, alkylphenols, nitrophenols and cresols in agricultural soils, analyzed by using gas chromatography-triple quadrupole-mass spectrometry. Journal of Chromatography A 1217:5724-5731. doi:10.1016/j.chroma.2010.07.004.
Przybylski, C., and V. Bonnet. 2009. Combination of $1 \mathrm{H}$ nuclear magnetic resonance spectroscopy and mass spectrometry as tools for investigation of the thermolytic and solvolytic effects: Case of carbamates analysis. Journal of Chromatography A 1216:47874797. doi:10.1016/j.chroma.2009.04.016.

Rashid, A., S. Nawaz, H. Barker, I. Ahmad, and M. Ashraf. 2010. Development of a simple extraction and clean-up procedure for determination of organochlorine pesticides in soil using gas chromatography-tandem mass spectrometry. Journal of Chromatography A 1217:2933-2939. doi:10.1016/j. chroma.2010.02.060

SAG. 2006. Estudio de residuos de plaguicidas en vegetales de consumo nacional. Servicio Agrícola y Ganadero (SAG), Ministerio de Agricultura, Gobierno de Chile, Santiago, Chile Available at http://www.sag.cl/sites/default/files/estudio_de_ residuos_plaguicidas.pdf (accessed May 2013).

SANCO. 2011. Method validation and quality control procedures for pesticide residues analysis in food and feed. Directorate-General for Health and Consumers (DG SANCO), Brussels, Belgium. Document nr SANCO/12495/2011. Available at http://ec.europa eu/food/plant/protection/pesticides/docs/qualcontrol_en.pdf (accessed May 2013).

Wilkowska, A., and B. Marek. 2011. Determination of pesticide residues in food matrices using the QuEChERS methodology. Food Chemistry 125:803-812. doi:10.1016/j.foodchem.2010.09.094. 